\title{
BLACK SEA AND THE CAUCASUS REGION; CAUSES OF INSTABILITY AND THE WAYS TO DEAL WITH THEM*
}

\author{
MUSTAFA AYDIN
}

\begin{abstract}
The collapse of the Soviet Union has changed international system and put the newly independent states of the Caucasus firmly into geopolitical calculations, which prompted disagreements, hostility, and possible armed interventions. In this context, this paper identifies the sources of unrest and threats to the stability of the Black Sea-Caucasus region. First, domestic sources of conflicts in the area, such as ethnic diversity, religious differences, economic inequality, and totalitarianism are explored. Secondly, the influence and foreign policies of number of countries active in the region are analysed, devoting particular attention to the attempts and inability of Russia to reconsolidate its power and hegemony. Third, the legal quandary over the definition of the Caspian Sea's status and the controversy surrounding the issue of transporting its natural resources out of the region are explored. The environmental issues in connection with the oil exploration activities in the Caspian Sea is also taken up. Finally, mechanisms for diffusing at least some of the controversies and threats are discussed within the context of the prospects awaiting the region in the mid-to-long term.
\end{abstract}

\section{KEYWORDS}

Caspian Basin; Ethnic Diversity; Caucasus; Great Game; Caucasian Stability Pact.

\footnotetext{
${ }^{*}$ This is a text of a paper delivered to International Conference on "GUUAM: Problems and Prospects for the Development of Transportation and Communication Corridors", July 3-6, 2001, Crimea, Ukranie.
} 
The changes experienced in international politics since 1989 have significantly altered the geopolitics of Eurasia, and the sudden emergence of the newly independent states (NIS) in place of former Soviet Union caught the world at large unprepared. The fact that no major empire has dissolved in this century without their successor states undergoing civil wars or regional conflicts made the occasion more dramatic.

During most of the twentieth century, the strategists and geopolitical experts considered the lands beyond the Caucasus Mountains and the Black Sea as Soviet Union's hinterland. The other superpower (i.e., the United States) simply tried to "contain" these areas by linking its various alignment systems. Thus, Turkey, Iran and Pakistan became important outposts of this policy, while Korea and Vietnam became its battleground, and China was useful in the chain insofar as it quarrelled with the Soviet Union.

However, the collapse of the Soviet Union has changed this situation dramatically, putting the NIS of greater Caspian region firmly into geopolitical calculations. ${ }^{1}$ This is both because it was discovered that some of them sit on vast natural resources, notably oil and gas, and because some of them were immediately engulfed in what was described as ethnic conflicts. Even in those countries that so far have avoided unrest and conflicts, the competition between various outside powers for influence threatened widespread disagreements, hostility and possibly armed interventions.

Moreover, during the Cold War, the world's attention, preoccupied by the possible results of a nuclear confrontation between the two blocs, had naturally focused on the global balance of power and strategic stability. Today, on the other hand, as there is no longer a superpower rivalry, world attention has turned towards the unfolding complexities of ethnic-based regional conflicts.

\footnotetext{
${ }^{1}$ For a defition of the "Greater Caspian" see M. Aydin, New Geopolitics of Central Asia and the Caucasus: Causes of Instability and Predicament, Ankara, Center for Strategic Research, 2000, pp. 10-13.
} 
In this context, it is worth mentioning that out of 28 wars fought in 1999 throughout the world, 19 were intra-state wars and at least 15 of them involved secession demands. What is more important for our purpose is four of these wars (NagornoKarabakh, Abkhazia, South Ossetia and Chechnya - five if we count 1994-1996 and Russia's current Chechen imbroglio as two separate wars) were fought in the Caucasus area, making the region one of the hot spots of the world. All of these were for secession and three of them (Nagorno-Karabakh, Abkhazia, South Ossetia) have become protracted frozen conflicts, where exchanges of fire may start at any given moment.

As there are many more possibilities for conflict in the region, the purpose of this paper is first to identify the sources of unrest and possible threats to the future stability of this region, and then speculate about the mechanisms for diffusing at least some of the controversies within the context of mid-to-long-term prospect of the region. The GUUAM and other proposed regional organizations would come into the discussion at this point.

We can project a number of interrelated and overlapping levels of threat to security and stability in the region, emanating from both within and without.

First of all, we have to mention domestic sources of conflicts in the area, such as ethnic diversity, religious differences, economic inequality and less than fully democratic governance throughout the region.

In addition to the challenges of economic and political transition, Caucasian states, after declaring independence, have had to contend with populations searching for and developing a sense of national identity. Thus, from the first day of their independence, they had faced the all-imposing task of the necessity to replace the now "discredited" socialist ideology and the social and economic model based upon it with a new thinking that could also help them to define their separate "identities".

Although three union republics were formed in the Caucasus, the Soviet period contributed little to support national identities. The borders of these states did not create homogeneous republics. Rather, they divided people. The end result was a poisonous 
mixture of various local, tribal and ethnic groups. Even a casual look today at the ethnic overlap within the region as well as the artificial nature of the boundaries clearly indicates to potential crises based on nationality questions. During the Soviet era, the destabilising effects of ethnic and religious diversity were kept under control by strict authoritarian control and suppression. However, the root causes of instability were never dealt with, which eventually contributed to the region's turmoil as the forces of destruction were unleashed following the collapse of the Soviet Union.

Although each independent Transcaucasian state has its own dominant titular nation, each also has significant number of minorities. The situation is further complicated by the diversification of religious faiths that are closely related to separate national and ethnic identities. Azerbaijan contains within its borders the Nagorno-Karabagh Autonomous Region, with a population mostly Armenians, while the Nakichevan Autonomous Republic, which consists mostly of Azeris, is a detached enclave sandwiched between Armenia and Iran. Moreover, the Azeris have compatriots living in Iran's northwestern province of Azerbaijan (between 15 to 25 million people). Thus the Azeris are aware of being artificially divided into two states. This complicates their relations with Iran that is deeply concerned about the possibility of rising ethnic separatism among its own Azeris. Georgia for its part, includes the Abkhazia Autonomous Republic, the Adzharia Autonomous Republic, and the South Ossetian Autonomous Region, with sizeable minorities and secessionist movements.

More complicated then this is the existing situation in the North Caucasus. With its nineteen native national groups, recognised by the last Soviet census of 1989 , and a significant ethnic Russian Diaspora as well as non-titular populations of Cossacks, Nogai, and number of others, the North Caucasus is one of the most ethnically and linguistically diverse regions of the world. The situation in the North Caucasus has been complicated further by the sharing of the same territory by several minorities and more than one titular nationality. In contrast, Dagestan is distinguished by its lack of titular national groups, and incorporates ten non-titular national groups that are recognised officially as "Peoples of Dagestan". Obviously, all of the North 
Caucasian "nationalities" is prone to instability and conflict in the future.

Another hotly discussed aspect of the identity question is the role of religion, and especially the rising fears about the influence of radical Islam in the region. It is obvious today that the long periods of Russian imperial rule and atheistic Soviet-era indoctrination have failed to eliminate the influence of Islam in the region as an important element of individual and collective selfidentity.

There is of course a danger in the North Caucasus that radical Islam could grow as a result of the unpredictable changes, disillusioned hopes, economic deprivation and lack of employment opportunities. Preventing an upsurge in Islamic militancy and the emergence of Islamic-oriented governments was sometimes claimed as a primary objective of both Russia and the West in the Caucasus. Consequently, it was this concern that promoted the socalled Turkish model of development superior to the Iranian model, representing the Islamic alternative. Later on, same concern led some Western analysts to view reassertion of Russian power as the lesser devil. On the other hand, Russia, too, used the same pretext to retain its military forces in the region.

Though religious fanaticism could turn out to be a dangerous factor in the future, especially as an ideological vehicle to mobilise the masses, it has not been a significant source of conflict so far throughout the Caucasus. No doubt, the post-Soviet search for historical roots and identity has led to growing interest in Islam. But, political Islam, as opposed to a purely cultural interest in the religion, has yet to make a significant mark. Thus, excepting the Chechens, Islam, at present, does not play an important political role with most of the Caucasian nationalities, and it could be argued that a union of all the Moslem peoples of the North Caucasus within a single Islamic state is utopian, and the prospect for establishing an Islamic republic along the lines of Iran in the region is weak.

Other domestic sources of instability are related to the economic conditions exist in the region. The Caspian region offers tremendous economic opportunities in the post-Soviet world. However, possible uneven development patterns are a significant 
potential source of instability in the region. Differences in the natural resource bases could provoke economically driven migration, polarise ethnic groups, and cause increased tensions. This combined with widespread unemployment creates potential for conflict.

It is also worth considering what effect the anticipated wealth resulting from these natural resources will have on the regional problems and the potential for confrontation. There are concerns, for example, that countries gaining most from the exploitation of natural resources might use their newly gained wealth to increase their military spending, thus creating a destabilising change in the regional balance of power.

On the other hand, the rapid economic and social changes since the collapse of the Soviet Union have left many people with a much lower standard of living than they previously had, and without the social safety net that they had benefited under the Soviet regime. These rapid changes and economic pressures have already led to a marked increase in personal corruption with its negative impact on regional stability. Since the independence, bribery and other corrupt practices offered a way for people to supplement their incomes in the unstable economic environments.

Another aspect of economic underdevelopment throughout the region is the strong desire to exploit the region's reaches as soon as possible. However, the end result of this hasty development effort might be the ruin of the Caspian's unique ecosystem accompanied by an irreversible environmental catastrophe.

Still within the domestic sources of instability, we have to mention the role of political ideology that has replaced communism in the region, that is authoritarianism. All the regional leaders have concluded that, given present conditions in their countries, a period of authoritarian rule is a necessary stage in the transition from communist totalitarianism to liberal democracy. Thus, while the struggle for national identification goes on within each republic, authoritarianism provides a tempting solution as "the only way to keep the country together". However, this may be a source of long-term trouble as it puts a lid on boiling problems, preventing ventilation and possibly causing violent eruptions in the longer term. 
Secondly, we have to discuss the influence and foreign policies of a extra-regional countries active in the region, devoting particular attention to the attempts and inability of Russia to reconsolidate its power and hegemony.

The initial power vacuum created in the region by the collapse of the Soviet Union has attracted many regional states and external powers into a dangerous game. Among the countries envisioned as key players the Russian Federation, Turkey, Iran, the United States, and the European Union, appear more active in the region. Obviously, each country has specific objectives, and the competition has economic, political, ideological and religious dimensions. As such, there exist various potentials for conflict among regional rivals.

While Russia initially welcomed Turkish influence in the region as a counterweight against Iranian dominated pan-Islamism, these views by now have shifted, and became itself more aggressive in asserting its "rights in its near abroad". In this move political, economic and military pressures have been used extensively, even arguing that stability in the region would be threatened without a Russian presence.

On the other hand, Turkey and Iran became rivals trying to create spheres of influence. Thus, for a while a competition emerged between two opposing models of political development for the Turco-Moslem peoples of the region: the secular model of Turkey with political pluralism and the Islamic model supported by Iran. In the meantime, Russian-Iranian relations rapidly developed after initial suspicions and reached an all-time high, with Iran becoming not only an important trading partner and profitable arms customer, but also an important exponent of Moscow's interests in the region and a counter against the growing influence of the United States.

What is presently more important on a more general level, we are witnessing the emergence of two rival groups or loosely defined political alliances in the region. There are the Russian Federation, Armenia and Iran on the one side, and the United States, Azerbaijan, Georgia and Turkey on the other. The long- 
term implications of this kind of confrontation are too obvious to warrant a further discussion here.

We also have to mention that it is the constant Russian manoeuvring in the Caucasus that has been the most important destabilising factor. Russia wishes to keep its hold over the area, but its own serious economic problems and political weaknesses hampers its efforts to restore its hegemony. Thus, while Russia is very sensitive to growing foreign presence and influence in the region and tries to curb both, its influence continues to decline. Therefore, despite dire consequences, there flew contradictory and uncoordinated actions towards the region from Russia. This creates an ambiguous and uncertain situation throughout the region and makes it all the more difficult for others to come to terms with the regional realities.

Third, the legal quandary over the definition of the Caspian Sea's status and the controversy surrounding the issue of transporting natural resources out of the region have to be explored. In this context, the serious questions concerning environmental and ecological issues arising from oil exploration activities in the Caspian Sea also need to be elucidated.

The attention of the wider international community turned to the region because of its rich natural resources. Therefore, international competition for access to oil and gas reserves and the need to bring them to world markets had both positive and negative effects on regional conflicts. Obviously, the full potential of regional wealth can only be enjoyed widely if its energy resources have a stable access to international markets. This motivates regional states to co-operate and provides an incentive for international efforts to resolve the region's conflicts. At the same time, however, the competition among the countries wishing to host the pipelines out of the region creates possibilities for conflicts.

During the Soviet period, most of the Caspian Sea coastline, apart from a small Iranian portion on the South, belonged to the Soviet Union. Since the collapse of the Soviet Union, five states have shared the coastline and claimed further authority over parts of the Sea area. Although it is not difficult to see the urgent need for an explicit definition of the legal status of Caspian, the ongoing 
discussion among the riparian states has tended to perpetuate over the issue of the sea/lake controversy while the real problem appears to be that of sharing the profit. Obviously, the undetermined status of the Caspian Sea not only prevents potential earnings of regional countries from foreign direct investments for exploitation and transportation of the hydrocarbon deposits under the Caspian seabed, but it also creates an unstable and explosive regional system.

Another peculiar feature of the Caspian oil is the fact that the countries that are most interested in early exploration and transportation of the oil and natural gas are landlocked and have to rely on co-operation of their neighbours. As each country has its preference regarding how the oil and natural gas should be transported to the world markets, and external powers are trying to exert influence to ensure that selected routes best meet their needs, this issue assumes an importance quite separate from that of production.

Under the current geopolitical calculations, Russia is keenly interested in retaining, or recovering, its political influence over the Caspian Basin. In order to acquire this leverage, Russia insisted that the Northern line from Baku, Azerbaijan to the Russian Black Sea port of Novorossiysk should be the main transit route for the future oil from the Caspian as this would ensure Moscow's exclusive and strategic control over the region's resources.

Opposing Russia's insistence on the Northern route, the United States and Turkey, as well as Georgia and Azerbaijan in the Caucasus, prefer the Western route through Georgia to the Turkish Mediterranean port of Ceyhan. Although there have been various projects, the main competition appears to be between the Northern and Western routes. What is at stake are not only oil and gas transit revenues that countries can extract from the pipelines passing through their respective territories, but more importantly, the pipeline network is considered as one of the key factors of securing and maintaining influence throughout Central Asia and the Caucasus. Hence, there is increasing scope for major clashes of interests in the region, particularly intensified after the arrival of extra-regional players. 
The US support for the Western route is firmly embedded in its wider Eurasian and Middle Eastern strategic priorities. One of them is to prop up the independence of the newly independent countries of Central Asia and the Caucasus against the influence of Russia. Another strategic goal of the US is to exclude Iran from participation in the production of Caspian oil and gas, and to prevent the development of transportation routes or pipelines that would lead from the Caspian region to either the Persian Gulf or the Indian Ocean via Iran. This objective is obviously connected with the fundamental US strategy in the Middle East of not permitting the emergence of any dominant regional power capable of influencing the oil market in the Gulf. Moreover, the US prefers the Turkish option, because this route passes through proAmerican countries in the region and would bind them closer to each other and to Western interests, which could check the influences of Iran and Russia in the region.

Obviously, if the Baku-Ceyhan pipeline is built and put into operation, it would weaken the economic and transport dependence of Central Asian and Caucasian states on Russia. Azerbaijan, Kazakhstan and Turkmenistan would emerge as new competitors for Russia's exports of oil and gas to the world market, and would use these earnings to enhance their political independence from Russia. The role of the Western states, whose oil and gas companies would eventually provide necessary investments, will increase, as will the role of Turkey. On the other hand, the perceived decrease in Russian influence or outside attempts to isolate or eliminate Russia in the Caspian Region can easily become counterproductive, and may quickly encounter an asymmetric response potentially destructive to the stability of regional security.

Finally, let us look at some of the possibilities for regional cooperation and the ways to diffuse the conflict potential in the region.

One way to help cultivate stability is to encourage regional interactions and co-operation. One of the emerging examples of co-operation within the region, with links to the outside world as well, is the establishment of TRACECA (TRAnsport Corridor Europe Caucasus Asia). It is hoped that this European Unionfunded project will enhance regional stability by facilitating the 
regional exchange of goods and creating a land-based link between Europe and the region.

But, one of the more effective ways to deal with regional security problems would of course be an arrangement for a regionwide common security organisation along the lines of the OSCE, with maybe a standing peacekeeping force from the regional states. However, there are various obstacles to overcome before such an arrangement can be applied to the region. First, there is the probable Russian resistance to sharing its much-sought role of "peacemaker" for the region. Second, it would be difficult to find regional states that would send and pay the costs of its soldiers in rather far away parts of Central Asia or the Caucasus to make or keep peace in conflicts that pose little immediate danger to their interests. Third, and maybe most importantly, the regional countries, both the older and newer ones, are not known for their co-operative tendencies, and they look at each other today with suspicion about intentions. So, almost none of the pre-conditions for setting up a regional common security organisation and conflict prevention mechanism exist within the region.

With this background, the outlook is not so bright and there are number of flash points that may erupt into an open armed conflict at any given time. Despite this, existing framework of political and economic cooperation systems in the region have not been adequate so far to promote peace and stability.

One of the reasons for failure of the existing cooperation aims in the region is their exclusive character, that is some countries are considered as potential members while others are excluded. The ECO and GUUAM are just two examples of this kind of organisations. Moreover, in both cases, the openly economic purpose of the organisations is mixed with extraeconomical aims that come into conflict with economic logic. Other existing organisations in the region like the CIS or the BSEC also mix political aims with economics. Moreover, most of their members only have a rather vague idea about the common interests of these organisations. Furthermore, some of these organisations are dominated by the interest of one or another member, which again impair the chances of the organisation in the long run. Therefore, in order to encourage economic cooperation and regional development, a more or less strict separation between 
organisations oriented towards the security and political cooperation and economic cooperation should be realized.

Another major problem facing the existing organisations in the region is the emergence of sub-national political entities, such as Chechnya, Nagorno-Karabakh, Abhazia, and South Ossetia, whose demands for independence creates problems for the peaceful development of the region. Moreover, the question of how to integrate and create a cooperative atmosphere between national and sub-national entities within an international or supranational organisation presents an important dilemma for international law. Therefore, before political and economic cooperation is achieved, it is necessary to recognise this problem and find an innovative way to harmonise the often-contradictory wishes of the nation-states and sub-national entities in the region.

Finally, the expectation that any organisation established in the region could address security issues and conflict resolution as well as providing adequate basis for economic cooperation and democratic reforms is elusive and hard to realise. It is a conventionally accepted wisdom that too much and widely formulated expectations from international organizations usually bring their end and failure.

Since the dissolution of the Soviet Union, several ideas for establishing international cooperative organisations in the Black Sea and Caspian Region were proposed. One of these proposals is the Caucasian Stability Pact, put forward by the then Turkish President Süleyman Demirel while visiting Tbilisi in 14-15 January this year (2000). The overwhelmingly positive answer he received both from regional countries and also from the world's leading countries, show that the need to establish such a cooperation arrangement in the region is now widely recognised. What is now required is to agree on the concrete form and the number of members.

Given above-mentioned problems with existing organisations, it is imperative that the aims as well as composition of such an organisation for regional cooperation have to be well defined and agreed on in advance. To separate political from economic goals for such an organisation, at least in the formative years, would a logical choice. Moreover, aiming for an inclusive 
membership as much as possible instead of disparate membership, that many proposals for regional cooperation so far appears to favour, should be the chosen route. Finally, such an organisation could utilize the previous experiences of Organisation for Security and Cooperation in Europe, instead of trying to develop new organisational and legal framework from scratch. The OSCE has already developed a functioning administration and a working set of regulations that have to be adjusted for regional use.

Logical result of above causations is to establish two parallel organisations, i.e., Organisation for Security and Cooperation in Eurasia for conflict resolution and political cooperation and Organisation for Economic Cooperation in Eurasia with economic aims, both including all the regional countries and closely cooperating with eachother. In this way, we may hope to bring peace and stability to this turbulent region. 